\title{
LOS PRINCIPALES ELEMENTOS DE MI FILOSOFÍA DEL DERECHO *
}

Robert Alexy

Universidad de Kiel

RESUMEN. En este texto R. Alexy expone las líneas básicas de su concepción de la filosofía del Derecho.

Palabras clave: R. ALEXY, pretensión de corrección, teoría del discurso, positividad, validez, constitucionalismo democrático.

ABSTRACT. R. ALEXY presents herein the main lines of his legal philosophy conception.

Keywords: R. ALEXY, claim to correctness, discourse theory, facticity, validity, democratic constitutionalism.

* Fecha de recepción: 28 de marzo de 2009. Fecha de aceptación: 28 de marzo de 2009.

Original: Hauptelemente meiner Philosophie des Rechts. Traducción: A. D. Oliver-LaLAna. 


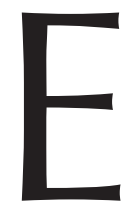

n el centro de mi filosofía jurídica se encuentra la tesis de que el Derecho tiene una doble naturaleza ${ }^{1}$. Comprende necesariamente tanto una dimensión real o fáctica como una dimensión ideal o crítica. El aspecto fáctico se refleja en los elementos definitorios de la legalidad conforme al ordenamiento y de la eficacia social, y el ideal en el de la corrección moral $^{2}$. Quien define el Derecho exclusivamente por medio de la legalidad conforme al ordenamiento y la eficacia social sostiene un concepto positivista de Derecho. En cuanto añadimos la corrección moral como tercer elemento necesario, el cuadro cambia de un modo fundamental: surge un concepto no positivista de Derecho. Así pues, la tesis de la doble naturaleza implica el no-positivismo.

Como tal, la tesis de la doble naturaleza del Derecho es todavía indeterminada y formal, pero adquiere un contenido concreto y una estructura clara cuando se despliega en un sistema. La idea rectora de este sistema es la institucionalización de la razón ${ }^{3}$, cuya forma política es el constitucionalismo democrático ${ }^{4}$. El sistema se puede generar en tres pasos.

\section{CORRECCIÓN Y DISCURSO}

\subsection{La pretensión de corrección}

El primero de los pasos estriba en la tesis de que el Derecho, necesariamente, efectúa o plantea una pretensión de corrección. Para precisar esta tesis hay que responder a tres cuestiones: a) ¿qué significa que el Derecho plantea una pretensión?; $b$ ) ¿qué hemos de entender por necesidad de la pretensión? y c) ¿en qué consiste el contenido de la pretensión?

\subsubsection{El planteamiento de la pretensión}

En sentido estricto, las pretensiones sólo pueden plantearlas sujetos capaces de actuar y de hablar ${ }^{5}$. De ahí que el Derecho, en la medida en que se contemple como un sistema de normas, no pueda plantear pretensión alguna, según ha puesto acertadamente de relieve N. MACCORMiCK ${ }^{6}$. Que el Derecho plantee una pretensión de corrección sólo puede significar, por tanto, que la plantean aquellos que intervienen en el Derecho, y actúan por él, al crearlo, interpretarlo, aplicarlo y hacerlo cumplir. Los casos paradigmáticos son el del legislador y el del juez. Que ellos planteen esa

\footnotetext{
1 R. Alexy, «On the Concept and the Nature of Law», Ratio Juris, 21, 2008, p. 292.

2 R. AleXY, El concepto y la validez del Derecho, trad. J. M. SEÑA, Barcelona, 1997, 2. ${ }^{a}$ ed., pp. 21 y ss.

3 R. Alexy, «La institucionalización de la razón», trad. J. A. SEOAne, en Persona y Derecho, 43, 2000, pp. 217 y ss.

${ }^{4}$ R. ALEXY, «La institucionalización de los derechos humanos en el Estado constitucional democrático», trad. M. C. AÑaños MeZA, en Derechos y libertades, 8, 2000, pp. 35 y ss.

5 R. Alexy, «Derecho y corrección», trad. J. A. SeOANE y E. R. Sodero, en R. Alexy, La institucionalización de la justicia, ed. J. A. SEOANE, Granada, Comares, 2005, pp. 32-33.

6 N. MacCormicK, «Why Law Makes No Claims», en G. Pavlakos (ed.), Law, Rights and Discourse, Oxford, Hart, 2007, p. 60.
} 
pretensión significa, primero, que a sus actos institucionales —es decir, a las decisiones legislativas y a las sentencias judiciales - está unido el acto no institucional de aserción o afirmación de que el acto jurídico es procedimental y materialmente correcto. La corrección implica justificabilidad. Luego la pretensión de corrección incluye, en segundo lugar, una aseveración de justificabilidad ${ }^{7, *}$. Como tercer elemento, a la afirmación y a la aseveración se suma la expectativa de que todo aquel que se sitúe en el punto de vista del correspondiente sistema jurídico y sea razonable aceptará el acto jurídico como correcto. El planteamiento de una pretensión de corrección, por consiguiente, se compone de la tríada de: 1) afirmación de la corrección, 2) aseveración de la justificabilidad, y 3) expectativa de aceptación. Esta tríada no se halla unida solamente a actos institucionales como las decisiones legislativas y las sentencias judiciales. Cualquiera que, en cuanto participante en un sistema jurídico — por ejemplo, como abogado ante un tribunal o como ciudadano dentro de un debate público--, aduzca argumentos a favor o en contra de determinados contenidos de dicho sistema estará planteando la pretensión integrada por la afirmación de la corrección, la aseveración de la justificabilidad y la expectativa de aceptación.

\subsubsection{La necesidad de la pretensión}

La pretensión de corrección sólo es relevante para el concepto y la naturaleza ${ }^{8}$ del Derecho si este la plantea necesariamente. Se puede demostrar y explicar su necesidad por medio de dos ejemplos.

El primer ejemplo trata del artículo primero de una nueva constitución para el Estado $X$, donde una minoría oprime a la mayoría. La minoría desea continuar disfrutando de las ventajas de oprimir a la mayoría, aunque también quiere ser sincera. La asamblea constituyente aprueba por ello, como artículo primero de la nueva constitución, la siguiente cláusula:

«1. $\mathrm{X}$ es una república soberana, federal e injusta».

Este artículo constitucional tiene algo defectuoso. La cuestión es únicamente en qué consiste el defecto. Sin duda, el artículo infringe las convenciones acerca de la redacción de textos constitucionales. Pero esto solo no explica el defecto. Por ejemplo, un catálogo de derechos fundamentales de cien páginas que intentara codificar la jurisprudencia dictada hasta la fecha por el tribunal constitucional sería de lo más insólito o poco convencional, pero no tendría el carácter manifiestamente absurdo de la cláusula de la injusticia. Ocurre otro tanto si pensamos en un defecto moral. Desde

7 R. AleXY, «Thirteen Replies», en G. Pavlakos (ed.), Law, Rights and Discourse, Hart, Oxford, 2007, pp. 348-49. En anteriores trabajos hablaba de una «garantía» en vez de una «aseveración» (Versicherung); cfr. ALEXY, «Derecho y corrección» (nota 5), p. 35.

* En el pasaje citado en la nota 7, el autor emplea la expresión «afirmación de justificabilidad» (affirmation of justifiability), en el sentido de una pretensión de tener razones válidas (the claim to bave sound reasons lies between the claim simply to have some reasons, whether sound or not, and the guarantee of soundness); cfr. también la nota 15. Al haberse usado ya la palabra «afirmación», se opta por traducir Versicherung como «aseveración» (aseverar es «afirmar o asegurar lo que se dice») [N. del T.].

8 Sobre la relación entre concepto y naturaleza, $c f r$. AlEXY, «On the Concept and the Nature of Law» (nota 1), pp. 290-92. 
el punto de vista de la moral, no habría ninguna diferencia si la mayoría oprimida fuese privada de forma expresa, en un artículo adicional, de los derechos a cuya privación apunta la cláusula de la injusticia. Pero desde el punto de vista del defecto, en cambio, sí existiría una diferencia: la cláusula de la injusticia no es sólo inmoral, sino en cierto modo también disparatada. E. BULYGIN ha sostenido que la cláusula de la injusticia constituye sólo un error político, pues sería «políticamente poco conveniente» ${ }^{9}$. Y seguramente lo es, aunque tampoco eso explica por completo el defecto. Muchas cosas en una constitución pueden ser inconvenientes en términos políticos y, en este sentido, técnicamente defectuosas, pero no provocan un efecto tan peculiar como nuestro artículo primero ${ }^{10}$. Ni el defecto convencional ni el moral ni el técnico explican el carácter absurdo de la cláusula de la injusticia. Ese carácter, como muy a menudo sucede con lo absurdo, resulta aquí de una contradicción. Tal contradicción surge porque con el acto de promulgar la constitución se plantea una pretensión de corrección, que en este caso es esencialmente una pretensión de justicia ${ }^{11}$. Como hemos visto, las pretensiones incluyen afirmaciones. Y la que está incluida en la pretensión de justicia planteada aquí es la afirmación de que la república es justa. La contradicción consiste, por tanto, en que con el acto de promulgar la constitución se efectúa implícitamente una afirmación que contradice el contenido explícito del acto constituyente, la cláusula de la injusticia ${ }^{12}$.

En el segundo ejemplo se trata de un juez que pronuncia el siguiente fallo:

«2. Se condena al acusado, en virtud de una interpretación errónea $(f a l s c h)$ del Derecho vigente, a cadena perpetua».

Esta frase suscita una serie de cuestiones que no se abordarán en este trabajo ${ }^{13}$. Lo único importante, en el presente contexto, es que reconocer un defecto convencional, moral o técnico, al igual que una vulneración del Derecho positivo ${ }^{14}$, no basta tampoco aquí para aprehender el peculiar carácter de la deficiencia. La absurdidad de la frase, también en este caso, se explica solamente por una contradicción. Con un fallo judicial se efectúa siempre la pretensión de que el Derecho es aplicado correctamente, por poco satisfecha que resulte. Esta pretensión de corrección, efectuada al ejecutarse el acto institucional de condena, contradice la calificación de erróneo que el fallo hace de sí mismo. Que se efectúe una pretensión de corrección significa, entre otras cosas, que se afirma implícitamente que el fallo es correcto. Esta afirmación implícita contradice

\footnotetext{
9 E. Bulygin, «Alexy y el argumento de la corrección», trad. P. GAido, en R. AlEXy y E. Bulygin, La pretensión de corrección del Derecho. La polémica Alexy/Bulygin sobre la relación entre Derecho y moral, Bogotá, Universidad Externado de Colombia, 2001, p. 50.

${ }^{10}$ Cfr. AlEXY, El concepto y la validez del Derecho (nota 2), p. 42.

${ }^{11}$ La justicia no es sino un caso especial de corrección, a saber: corrección en relación con la distribución y la compensación; $c f r$. R. AleXY, «Justicia como corrección», trad. A. I. HAQuín, en Doxa, 26, 2003, p. 163.

12 Sobre este punto, con mayor detalle, R. ALEXY, «Sobre la tesis de una conexión necesaria entre Derecho y moral: la crítica de Bulygin», trad. P. GAIDO, en: R. ALEXY y E. BULYGIN, La pretensión de corrección del Derecho. La polémica Alexy/Bulygin sobre la relación entre Derecho y moral, Bogotá, Universidad Externado de Colombia, 2001, pp. 100 y ss.

${ }_{13}$ Cfr., al respecto, por una parte, U. Neumann, Juristische Argumentationslebre, Darmstadt, Wiss. Buchgesellschaft, 1986, pp. 87-89, así como BULYGIN, «Alexy y el argumento de la corrección» (nota 9), pp. 49-50; y, por la otra, R. ALEXY, «La crítica de Bulygin al argumento de la corrección», trad. P. GAIDO, en: R. ALEXY y E. Bulygin, La pretensión de corrección del Derecho. La polémica Alexy/Bulygin sobre la relación entre Derecho y moral, Bogotá, Universidad Externado de Colombia, 2001, pp. 78-83.

${ }^{14}$ ALEXY, El concepto y la validez del Derecho (nota 2), p. 44.
} 
la afirmación explícita y pública, unida al fallo, de que éste es erróneo. Esta contradicción entre lo implícito y lo explícito explica el absurdo.

Cabría objetar que todo esto aún no muestra la necesidad de la pretensión de corrección, ya que en los dos casos el absurdo sería evitable. Tan sólo habría que modificar radicalmente la praxis y la concepción del Derecho vigentes hasta ahora. Una vez que todos interpretasen las constituciones exclusivamente como una expresión de poder, voluntad y fuerza, y las sentencias judiciales como una mezcla de órdenes, decisiones y emociones, o sea, si ambas cosas se entendieran como naturales, desaparecería de nuestros ejemplos la pretensión de corrección y, con ella, desaparecería a un tiempo la contradicción y, por ende, el absurdo. La pretensión de corrección quedaría sustituida por algo así como una pretensión de poder. Esta posibilidad de sustituir el Derecho por el mero poder muestra en qué sentido es necesaria la pretensión de corrección. Y es necesaria con relación a una práctica definida esencialmente por la distinción entre lo correcto y lo erróneo o incorrecto (falsch), es decir, por la normatividad. Esta práctica es, por cierto, una práctica de índole especial. Podríamos desde luego intentar prescindir — sea totalmente o sólo en el ámbito de la coordinación y la cooperación sociales- de las categorías de corrección, justificabilidad y objetividad ${ }^{15}$. Pero si lográsemos hacerlo, nuestro lenguaje y nuestros actos (Reden und Handeln) serían algo sustancialmente distinto de lo que ahora son. El precio a pagar por ello sería alto: en algún sentido, consistiría en nosotros mismos. Por tanto, la fundamentación de la necesidad de la pretensión de corrección, si quiere ser algo más que la explicación de una práctica presente en la realidad, conduce a una dimensión existencial ${ }^{16}$.

\subsubsection{El contenido de la pretensión}

Con la tesis de que el Derecho plantea una pretensión de corrección todavía no se dice nada sobre el contenido de esa pretensión. Este depende del contexto institucional. Y así, para una asamblea constituyente se aplicarán criterios distintos de los aplicables a las sentencias judiciales. Pero hay dos rasgos que caracterizan la pretensión de corrección del Derecho en todos los contextos: la primera es que incluye siempre una pretensión de justificabilidad; y la segunda es que, como se expondrá luego, siempre se refiere - por lo menos también - a la corrección moral. De esta manera, al dictar un fallo o sentencia judicial no sólo se afirma que se ha seguido el Derecho promulgado

15 RAZ ha sostenido que el argumento de la corrección no es más que una «tesis general sobre las acciones intencionales y sus productos», de modo que valdría también para las acciones de los bandidos. Ahí tomaría la forma de una pretensión de que aquello que hacen los bandidos es idóneo o «apropiado» (appropriate) en relación con sus objetivos, lo cual podría significar, por ejemplo, que la acción resulta lucrativa o «auto-enriquecedora» (self-enriching); J. RAZ, «The Argument from Injustice, or How Not to Reply to Legal Positivism», en: G. Pavlakos (ed.), Law, Rights and Discourse, Oxford, Hart, 2007, p. 27. A ello hay que responder que la pretensión de corrección, según se ha expuesto, incluye una aseveración de justificabilidad que se hace frente a todos, así como una expectativa de aceptación. El objetivo de enriquecerse uno mismo mediante el robo no es compatible con esto. La pretensión de idoneidad a la que alude RAZ carece, pues, de la dimensión de objetividad contenida en la pretensión de corrección. Cfr. R. ALEXY, «An Answer to Joseph Raz», en G. PAVLAKOS (ed.), Law, Rights and Discourse, Oxford, Hart, 2007, p. 49.

${ }_{16} \mathrm{Cfr}$., al respecto, R. ALEXY, «Menschenrechte ohne Metaphysik?», Deutsche Zeitschrift für Philosophie, 52,2004 , p. 21. 
y eficaz, sino también que tanto este Derecho como su interpretación son moralmente correctos.

\subsection{La teoría del discurso}

Cabría objetar que la pretensión de corrección, por cuanto se refiere a la moral, es tan sólo expresión de una ilusión. Los juicios sobre lo que está moralmente ordenado, prohibido o permitido, sobre lo que es bueno y malo y justo e injusto, serían subjetivos, relativos y fruto de meras decisiones. Las cuestiones prácticas, dejando al margen las que atañen a la maximización de la utilidad, serían racionalmente indecidibles. A esta objeción del irracionalismo hago frente con la teoría del discurso.

\subsubsection{Las ideas fundamentales de la teoría del discurso}

La teoría del discurso es una teoría procedimental de la corrección o verdad práctica ${ }^{17}$. La tesis principal de todas las teorías procedimentales de la corrección es que la corrección de una proposición normativa depende de que la proposición sea o pueda ser el resultado de un determinado procedimiento. Es una propiedad esencial de la teoría del discurso que este procedimiento no sea un procedimiento de decisión o negociación, sino un procedimiento de argumentación.

El procedimiento del discurso puede definirse mediante un sistema de reglas discursivas que expresan las condiciones de la argumentación práctica racional ${ }^{18}$. Una parte de esas reglas formula exigencias generales de racionalidad, válidas también con independencia de la teoría del discurso. Entre ellas figuran la no contradicción, la universabilidad —en el sentido de un uso consistente de los predicados utilizados-, la claridad lingüística y conceptual, la verdad empírica, la consideración de las consecuencias, la ponderación, el intercambio de roles y el análisis del origen de las convicciones morales. Todas estas reglas son válidas asimismo para los monólogos. Ya esto deja claro que la teoría del discurso en ningún caso reemplaza la justificación o fundamentación por la mera creación de consensos, como se ha objetado en su contra ${ }^{19}$. Esta teoría incluye la totalidad de las reglas de argumentación racional que son aplicables a fundamentaciones monológicas. Su particularidad estriba exclusivamente en que a este plano le añade otro: el de las reglas referidas al procedimiento del discurso, las cuales tienen un carácter no monológico. Su objetivo es la imparcialidad del discurso. Y este objetivo se alcanza asegurando la libertad y la igualdad de la argumentación. Entre estas reglas, las más importantes rezan:

17 R. AleXY, «La idea de una teoría procesal de la argumentación jurídica», trad. C. DE SANTIAGO (rev. E. Garzón Valdés), en E. Garzón Valdés (ed.), Derecho y filosofía, Barcelona-Caracas, Alfa, 1985, pp. 43 y ss.

18 Para un intento de formular dicho sistema con ayuda de veintiocho reglas del discurso, $c f r$. R.

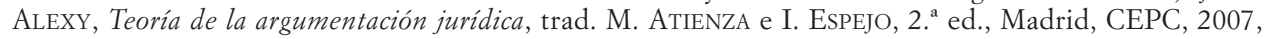
pp. 185-201.

19 Cfr. O. WeInBERGER, «Grundlagenprobleme des Institutionalistischen Rechtspositivismus und der Gerechtigkeitstheorie», en P. KOLLER, W. KRAWIETZ y P. STRASSER (eds.), Institution und Recht (Rechtstheorie, Beiheft 14), Berlin, Duncker \& Humblot, 1994, pp. 258-59. 
«(1) Quien pueda hablar puede tomar parte en el discurso.

(2) a) Todos pueden problematizar cualquier aserción.

b) Todos pueden introducir cualquier aserción en el discurso.

c) Todos pueden expresar sus opiniones, deseos y necesidades.

(3) A ningún hablante puede impedírsele ejercer sus derechos fijados en (1) y (2) mediante coerción interna o externa al discurso ${ }^{20} \gg$.

Estas reglas expresan las ideas de libertad e igualdad en el plano de la argumentación. Y si ellas valen, es decir, si todos pueden decidir libremente y en igualdad aquello que aceptan, vale entonces necesariamente la siguiente condición de aprobación o acuerdo universal:

«Una norma sólo puede encontrar aprobación universal en un discurso si las consecuencias de su observancia general respecto a la satisfacción de los intereses de cada uno de los individuos pueden ser aceptadas por todos».

Constituye una asunción central de la teoría del discurso, en primer lugar, que la aprobación en el discurso puede depender de los argumentos y, en segundo lugar, que existe una relación necesaria entre la aprobación universal bajo condiciones ideales y los conceptos de corrección y, por tanto, de validez moral. Esta conexión puede formularse como sigue:

«Únicamente son correctas y, por tanto, válidas las normas que en un discurso ideal todos juzgarían correctas».

\subsubsection{Los límites de la teoría del discurso}

La teoría del discurso conduce a numerosos problemas. Tres de ellos resultan de especial importancia. El primero, que afecta a la teoría del discurso como teoría de la corrección práctica, puede denominarse problema del estatus. El problema del estatus se refiere a la cuestión de si efectivamente existe, como sostiene la teoría del discurso, una relación necesaria entre los discursos y la corrección práctica ${ }^{21}$. El segundo problema reside en la fundamentación de las reglas del discurso. El problema de la fundamentación se puede resolver si se logra mostrar, por una parte, que quienes participan en la práctica de afirmar, preguntar y argumentar presuponen necesariamente esas reglas; y, por la otra, que la participación en esa práctica es, en algún sentido, necesaria para cualquier persona. He procurado exponer que tanto lo uno como lo otro es cierto ${ }^{22}$. Aquí será el tercer problema el que ocupe el primer plano. Es el problema de la aplicación de la teoría del discurso.

Desde el punto de vista de la aplicabilidad, la principal debilidad de la teoría del discurso estriba en que su sistema de reglas no ofrece un procedimiento que permita llegar a un único resultado en un número finito de operaciones. Esto obedece a tres razones. En primer lugar, las reglas del discurso no contienen estipulaciones sobre los

20 ALEXY, Teoría de la argumentación jurídica (nota 18), p. 189.

21 Sobre este punto, cfr. R. ALEXY, «Problemas de la teoría discurso», en Actas del Congreso Internacional Extraordinario de Filosofía, vol. 1, Córdoba (Argentina), Univ. Nacional de Córdoba, 1988, pp. 66-70; así como ALEXY, «Thirteen Replies» (nota 7), pp. 347-48.

${ }^{22}$ R. AleXY, «Teoría del discurso y derechos humanos», trad. L. Villar Borda, en R. AleXY, Teoría del discurso y derechos bumanos, Bogotá, Universidad Externado de Colombia, 1995, pp. 73-95. 
puntos de partida del procedimiento. Los puntos de partida son las convicciones normativas e interpretaciones de intereses de los participantes que existan en cada caso. En segundo lugar, las reglas del discurso no fijan todos los pasos de la argumentación. $\mathrm{Y}$ en tercer lugar, hay una serie de reglas del discurso que tiene carácter ideal y, por consiguiente, sólo son susceptibles de cumplimiento aproximado.

Esto último nos trae a la distinción, fundamental para la teoría del discurso, entre discursos ideales y reales. El discurso práctico ideal en todos los aspectos se define por ser un discurso en el cual, bajo condiciones de tiempo ilimitado, participación ilimitada y total ausencia de coerción, se busca la respuesta a una cuestión práctica sobre la base de una completa claridad lingüístico-conceptual, una información empírica perfecta, una completa capacidad y disposición para el intercambio de roles, y una total ausencia de prejuicios. El concepto de discurso ideal plantea diversos problemas ${ }^{23}$, y es objeto de duras críticas ${ }^{24}$. Ninguna persona ha participado nunca en un discurso ideal en todos los aspectos, y ningún mortal lo hará jamás. Por eso, sobre los resultados de discursos ideales nunca podrá haber certeza, sino tan sólo suposiciones. Además, ni siquiera es seguro que el discurso ideal en todos los aspectos condujese en cada cuestión práctica a un consenso, o que las personas no tengan diferencias que sean resistentes al discurso y excluyan los consensos incluso bajo las condiciones más ideales.

Todo eso, sin embargo, no es capaz de desvirtuar el concepto de discurso ideal. La noción del discurso ideal es una idea regulativa siempre presente en los discursos reales ${ }^{25}$; en cuanto idea regulativa, expresa su meta u objetivo. Lo que define los discursos prácticos reales es que en ellos se busca la respuesta a una cuestión práctica bajo condiciones de tiempo limitado, participación limitada y limitada ausencia de coerción; y con una claridad lingüístico-conceptual limitada, una información empírica limitada, una limitada capacidad para el intercambio de roles y una ausencia limitada de prejuicios. Aun a pesar de estas limitaciones, el discurso real se encuentra necesariamente vinculado al ideal. Quien intenta convencer a un oponente con argumentos presupone que este tendría que convenir con él bajo condiciones ideales. El discurso ideal, como idea regulativa, y la pretensión de corrección son, de este modo, dos caras de una misma cosa.

Contra ello se podría objetar que el discurso ideal es inútil como idea regulativa. Lo sería si aproximarse a él fuese o imposible o irrelevante para la corrección. Que la aproximación de los discursos reales a los ideales es posible resulta fácil de advertir. Y así, hay discursos limitados y discursos abiertos, imprecisos y claros, autocomplacientes y críticos; y todo esto, y más, aparece en diferentes grados. La cuestión, por tanto, sólo puede ser si existe una vinculación intrínseca entre la aproximación a los discursos ideales y la corrección práctica. Hay buenas razones para sostener que tal es el caso. En los discursos prácticos no se trata sólo de constatar intereses comunes, sino también, y primordialmente, de hallar una solución correcta a conflictos de intereses. En esencia, la solución correcta a los conflictos de intereses pasa por determinar correctamente los pesos relativos de los intereses que se encuentran en juego. Supongamos por ejemplo

23 ALEXY, «Problemas de la teoría discurso» (nota 21), pp. 50-57.

24 WeINBERGER, «Grundlagenprobleme des Institutionalistischen Rechtspositivismus und der Gerechtigkeits-theorie» (nota 19), pp. 259-262.

${ }_{25}$ Sobre el concepto de idea regulativa, cfr. I. KANT, Crítica de la razón pura, A 509, 644; B 537, 672. 
que la norma $N_{1}$, que resuelve un conflicto de intereses, encuentra aprobación general tras un discurso del que fueron excluidos los oponentes no dispuestos a aceptarla, y en el cual prevaleció un grupo, la retórica emocional dominó el terreno, los hechos falsos fueron tratados como verdaderos hasta el final, y los ganadores miraron exclusivamente por sus propios intereses y nada quisieron oír de los intereses de los demás. Compárese este escenario con la solución del mismo conflicto de intereses mediante la norma $N_{2}$, que encuentra aprobación general tras un discurso del que nadie ha sido excluido y en el cual nadie prevaleció, donde se argumentó con claridad y precisión, donde se hicieron sólo apreciaciones exactas o probables sobre las circunstancias empíricas, y donde todos, en la medida de sus posibilidades, se pusieron en la situación de los demás y discutieron entre sí su interpretación de los intereses. No hay duda de que el segundo caso está más próximo al discurso ideal que el primero, y todo indica que $N_{2}$, al menos ceteris paribus, se encuentra por ello más próxima a la corrección que $N_{1}$. Esto es suficiente para lo que se trataba de mostrar aquí: la aproximación del discurso real al ideal no es irrelevante para la corrección.

La vinculación del discurso real con el ideal, no obstante, sólo es capaz de eliminar la indefinición del resultado de manera muy limitada. Hay algunas cosas que, cuando se logra una aproximación suficiente al discurso ideal —lo cual, generalmente, es posible en la práctica一, no entran en consideración como resultado. Un ejemplo es la esclavitud. Esta se puede calificar como «discursivamente imposible» ${ }^{26}$. Otras cosas pueden conceptuarse con bastante seguridad como resultados del discurso, por lo que cabe denominarlas «discursivamente necesarias». Sirvan de ejemplo los derechos humanos y la democracia ${ }^{27}$. Ahora bien, en numerosos casos, puede ocurrir que se sostengan posiciones inconciliables al final de un discurso, sin que ello vulnere las reglas discursivas. Por su compatibilidad con las reglas del discurso, esas posiciones en conflicto pueden calificarse como «discursivamente posibles». El desacuerdo discursivamente posible es un desacuerdo razonable. Y aquí la teoría del discurso tropieza con un límite que ella misma no puede cruzar. Esto podemos llamarlo el «problema del conocimiento (Erkenntnis)».

\section{POSITIVIDAD}

El problema del conocimiento obliga a abandonar el primer nivel, definido solamente por los ideales de la corrección y del discurso, y a pasar a un segundo nivel en el que los procedimientos regulados por el Derecho positivo garantizan la toma de decisiones, por ejemplo, mediante votaciones en el Parlamento. Este es el paso a la positividad definida por la legalidad.

El problema del conocimiento no es el único problema que nos conduce desde la teoría del discurso pura al Derecho positivo. A él se suman otros dos: el problema de la imposición o ejecución y el de la organización. El problema de la ejecución surge porque la mera conciencia de la corrección de una norma no garantiza su observancia. Y si algunos pueden vulnerar una norma sin correr ningún riesgo, ya no se puede

\footnotetext{
26 AleXY, Teoría de la argumentación jurídica (nota 18), pp. 201-202.

${ }^{27}$ Cfr. Alexy, «Teoría del discurso y derechos humanos» (nota 22), pp. 104 y ss., 134 y ss.
} 
exigir a nadie más que la cumpla. Esto hace necesaria la conexión entre el Derecho y la coerción, por cuanto ésta es un elemento decisivo de la eficacia social ${ }^{28}$. Por último, el problema de la organización resulta del hecho de que numerosas exigencias morales y objetivos deseables no se pueden cumplir o alcanzar suficientemente tan sólo mediante acciones individuales y cooperación espontánea. La seguridad social es un ejemplo: su organización presupone Derecho. Y esto vale también para la administración del Derecho mismo: el Derecho tiene que organizarse a través del Derecho. Así pues, la tesis de la doble naturaleza conduce primero hasta la idealidad, en forma de corrección y discurso, y después hasta la facticidad, en forma de legalidad y eficacia.

\section{INSTITUCIONALIZACIÓN DE LA RAZÓN}

Se podría pensar que con el tránsito desde el discurso a la facticidad de la legalidad y la eficacia se da a la vez el paso hacia el positivismo jurídico ${ }^{29}$. Pero eso sería malentender la tesis de la doble naturaleza. Según la tesis de la doble naturaleza, el Derecho tiene necesariamente tanto una dimensión fáctica o real como una dimensión ideal o crítica. La necesidad de esta vinculación deriva de dos principios contrapuestos: el de seguridad jurídica y el de justicia. Como la pretensión de corrección incluye los dos principios ${ }^{30}$, ambos están necesariamente conectados al Derecho. El principio de seguridad jurídica reclama sujetarse a aquello que ha sido establecido conforme al ordenamiento y es eficaz socialmente; el de justicia exige la corrección moral de la decisión. Ninguno de los dos principios puede jamás desplazar por completo al otro. La tesis de la doble naturaleza exige combinar ambos en la proporción correcta. La corrección cobra, en esa proporción, un sentido que comprende facticidad e idealidad. También podría hablarse aquí de una «corrección de segundo nivel». Generar esta corrección de segundo nivel es tarea del tercer paso, en el que se aborda la institucionalización de la razón.

\subsection{El límite último}

La institucionalización de la razón es una empresa compleja. En ella pueden distinguirse cuatro aspectos. El primero lo constituye un límite extremo o último del Derecho. Aquí se trata de refutar la célebre frase de H. KELSEN: «por tanto, cualquier contenido puede ser Derecho» ${ }^{31}$. Lo que a su juicio puede llegar a ser Derecho lo ilustra KELSEN con este comentario: «con arreglo al Derecho de los Estados totalitarios, el gobierno está facultado para confinar a las personas de convicciones, religión o raza indeseadas en campos de concentración, para obligarlas a realizar cualquier tipo

28 ALEXY, «On the Concept and the Nature of Law» (nota 1), pp. 292-293.

29 Así, C. BRAUN, «Diskurstheoretische Normenbegründung in der Rechtswissenschaft», Rechtstheorie, 19, 1988, pp. 259-60.

30 AlEXY, «On the Concept and the Nature of Law» (nota 1), p. 293.

31 H. Kelsen, Teoría pura del Derecho (21960), trad. R. J. Vernengo, México, Porrúa, 1998, p. 205 [donde la frase se traduce: «de ahí que cualquier contenido que sea, pueda ser Derecho» (N. del T.)]. 
de trabajo, y hasta para matarlas» ${ }^{32}$. A esto hay que contraponer la fórmula de RADBRUCH $^{33}$, que en su versión abreviada puede expresarse asi ${ }^{34}$ :

«La injusticia extrema no es Derecho».

Lo que tiene de particular esta fórmula es que conecta Derecho y moral sin exigir una coincidencia plena entre ambos. Deja que el Derecho positivo sea válido aun cuando sea injusto ${ }^{35}$. Tan sólo si se traspasa el umbral de la extrema injusticia pierden las normas establecidas conforme al ordenamiento y socialmente eficaces su carácter jurídico o su validez jurídica.

La pretensión de corrección, ciertamente, constituye un importante apoyo para la fórmula de RADBRUCH, aunque, por sí sola, no basta para justificarla. Para ello son precisas razones adicionales. Entre estas razones, las normativas desempeñan un papel especial. Esto ya ha sido expuesto con detalle en otro lugar ${ }^{36}$, por lo que aquí se abordará solamente la cuestión fundamental de si las razones normativas, como los recién mencionados principios de seguridad jurídica y justicia, pueden jugar algún papel en absoluto de cara a determinar el concepto y la naturaleza del Derecho.

J. RAz ha sostenido que la cuestión de la naturaleza del Derecho es una cuestión teórica, y no práctica o normativa, y que la teoría exclusivamente ha de constatar «cómo son las cosas» ${ }^{37}$. En cuanto a la cuestión de si la fórmula de RADBRUCH dice algo correcto sobre la naturaleza del Derecho o si - como lo expresa RAZ— existe una regla «que confiere a los tribunales el poder de invalidar (set aside) leyes extremadamente injustas», estaríamos, pues, ante «una cuestión de hecho social (a matter of social fact) $)^{38}$. Pero que en todos los sistemas jurídicos exista necesariamente un hecho social semejante es algo que yo tendría que haber demostrado ${ }^{39}$. A esto hay que responder que la fórmula de RADBRUCH no describe ningún hecho social. Es, antes bien, la contraparte de un hecho social: impone límites a la validez jurídica sustentada en los hechos sociales de la legalidad conforme al ordenamiento y de la eficacia real.

No obstante, queda la cuestión de si la fórmula puede hacer eso sobre la base de razones morales, es decir, normativas. A. MARMOR lo niega con singular énfasis: «una vez que admitimos que para llegar a la fórmula de RADBRUCH necesitamos un argumento normativo, quedamos en manos de un argumento moral que nos diga algo sobre el Derecho. La conclusión, entonces, ya no es sobre la naturaleza del Derecho. Así de simple» ${ }^{40}$.

32 Ibid., p. 54.

33 G. RADBRUCH, «Gesetzliches Unrecht und übergesetzliches Recht», 1946, en G. RADBRUCH, Gesamtausgabe, vol. 3, Heidelberg, Müller, 1990, p. 89 («Leyes que no son Derecho y Derecho por encima de las leyes», trad. J. M. Rodríguez Paniagua, en G. Radbruch et al., Derecho injusto y Derecho nulo, Madrid, Aguilar, 1971, pp. 13-14).

34 Cfr. R. Alexy, «Una defensa de la fórmula de Radbruch», trad. J. A. SEOAnE, en Anuario da Facultade de Dereito da Universidade da Coruña, 5, 2001, pp. 75 y ss.

35 Atendiendo a esta fórmula cabe hablar, por lo tanto, de un «no-positivismo inclusivo»; cfr., al respecto, AlEXY, «On the Concept and the Nature of Law» (nota 1), pp. 286-290.

36 AleXY, El concepto y la validez del Derecho (nota 2), pp. 34-67. de R. A.

37 J. Raz, «On The Nature of Law», Archiv für Rechts- und Sozialphilosophie, 82, 1996, p. 7 —cursivas

38 RAZ, «How Not to Reply to Legal Positivism» (nota 15), p. 31.

39 Ibid.

40 A. Marmor, «Debate», Anales de la Cátedra Francisco Suárez, 39, 2005, p. 752. 
Se puede rebatir que sea así de simple. No es tan simple porque junto a la perspectiva del observador está la perspectiva del participante ${ }^{41}$, y porque la perspectiva del participante es necesaria para el Derecho y, por lo tanto, pertenece a su naturaleza. No existe Derecho sin participantes. La diferencia entre ambas perspectivas consiste en que el observador pregunta cómo se decide de hecho en un determinado sistema jurídico, mientras que el participante pregunta cuál es la respuesta correcta a una cuestión jurídica dentro de un determinado sistema jurídico. Para el observador, el Derecho se compone tan sólo de aquello que ha sido efectivamente promulgado y es socialmente eficaz ${ }^{42}$. Esto, en verdad, es «una cuestión de hecho social», como la llama RAz. En la perspectiva del participante, en cambio, la respuesta a la cuestión de qué tiene validez como Derecho y, en ese sentido, es el Derecho, depende de lo que se pueda afirmar correctamente que es Derecho. Y la corrección de una afirmación sobre lo que sea el Derecho no depende ya sólo de hechos sociales, sino también de argumentos morales. En este sentido, los argumentos morales forman parte de las condiciones de corrección de las afirmaciones jurídicas ${ }^{43}$. De tal suerte, lo que el Derecho debe ser penetra en lo que el Derecho es. El «es» del participante, por esta razón, es necesariamente un «es» que incluye un deber ser. Al igual que antes a propósito de la corrección, cabría asimismo hablar aquí de un «es» de segundo nivel.

\subsection{Constitucionalismo democrático}

El límite último de todo Derecho es una condición necesaria, aunque en ningún caso suficiente, para la institucionalización de la razón. Para lograrla no sólo hay que solventar la confrontación entre positividad y corrección en ese límite último o exterior, sino que también hay que establecer, en la medida en que sea posible, su vinculación en el interior. Y esto sólo es factible en la forma política del constitucionalismo democrático.

\subsubsection{Derechos fundamentales}

La teoría del discurso conduce al constitucionalismo democrático porque plantea dos exigencias cardinales respecto al contenido y a la estructura del sistema jurídico: derechos fundamentales y democracia. Los derechos fundamentales son derechos que han sido recogidos en una constitución con el propósito de positivizar los derechos humanos ${ }^{44}$. Los derechos humanos son derechos morales de índole universal, fun-

41 Cfr. Alexy, El concepto y la validez del Derecho (nota 2), pp. 31-32.

42 Esto no impide que las consideraciones del observador incluyan consideraciones acerca de cómo debe ser el Derecho según la opinión de los participantes que él observa. Cabe hablar aquí de «consideraciones indirectas» o «en tercera persona» acerca de cómo debe ser el Derecho. Los participantes, por el contrario, efectúan consideraciones directas o en primera persona.

${ }^{43}$ Cfr. R. Dworkin, Justice in Robes, Cambridge Mass., Harvard UP, 2006, p. 2, quien habla de «condiciones de verdad» (truth conditions) en lugar de «condiciones de corrección».

44 R. Alexy, «Los derechos fundamentales», trad. C. BeRnal Pulido, en R. AleXy, Tres escritos sobre los derechos fundamentales y la teoría de los principios, Bogotá, Universidad Externado de Colombia, 2003, p. 28. 
damental *, abstracta y prioritaria ${ }^{45}$. Como intentos de positivización de los derechos morales, los derechos fundamentales expresan la doble naturaleza del Derecho de un modo particularmente significativo.

Por supuesto, los derechos humanos pueden imponer exigencias al sistema jurídico sólo si existen. Y existen si son válidos. Pues bien, la validez de los derechos humanos como derechos morales depende de su justificabilidad, y de nada más.

Hace algún tiempo intenté una fundamentación de los derechos humanos, en términos de teoría del discurso, cuyo punto de partida es un argumento trascendental ${ }^{46}$. Este punto de partida se puede denominar también «explicativo» ${ }^{47}$. El argumento explicativo consiste en un análisis de la praxis discursiva, que es la práctica de afirmar, preguntar y aducir razones. Esta práctica presupone necesariamente reglas que expresan las ideas de libertad y de igualdad de los participantes en el discurso ${ }^{48}$. Desde luego, la libertad y la igualdad en el discurso aún no implican libertad e igualdad en el terreno de los actos. Para completar ese paso, hay que sumar a las capacidades discursivas un interés en utilizarlas efectivamente (im Handeln). Lo podemos denominar «interés en la corrección». Esta vinculación entre capacidad e interés implica reconocer al otro como autónomo ${ }^{49}$. Quien reconoce al otro como autónomo, lo reconoce como persona. Quien lo reconoce como persona, le atribuye dignidad. Quien le atribuye dignidad, reconoce sus derechos humanos. Y con ello hemos llegado al objetivo de la fundamentación.

Cabría objetar que esto no constituye en absoluto una fundamentación. Es cierto — se dirá - que la explicación de las presuposiciones necesarias de una práctica podría verse como una fundamentación si esta práctica hubiera de conceptuarse como necesaria. Tal sería el caso de la práctica de afirmar, de preguntar, y de dar y aceptar razones, al menos en la medida en que quien a lo largo de toda su vida no efectúa ninguna afirmación, no plantea ninguna pregunta y no aduce ningún argumento, no toma parte en lo que cabe llamar la «forma de vida humana más elemental» ${ }^{50}$. Pero el argumento para justificar los derechos humanos dejaría de ser una fundamentación tan pronto como entraran en juego los intereses.

Aunque acierta en algo, esa objeción ha de relativizarse. Como todo interés, el interés en la corrección se halla, en efecto, ligado a decisiones acerca de si se impone frente a intereses contrapuestos. Ahora bien, con esa cuestión nos encontramos ante la pregunta fundamental de si aceptamos nuestras posibilidades discursivas. Se trata de si nos queremos a nosotros mismos, en palabras de BRANDOM ${ }^{51}$, como criaturas discursivas. Eso es una decisión acerca de lo que somos. Este paso de la fundamenta-

* En el sentido de que son derechos que protegen necesidades e intereses fundamentales o básicos (N. del T.).

${ }_{45}$ ALEXY, «Menschenrechte ohne Metaphysik?» (nota 16), p. 16.

46 ALEXY, «Teoría del discurso y derechos humanos» (nota 22), pp. 73 y ss.

${ }^{47}$ Cfr. Alexy, «Menschenrechte ohne Metaphysik?» (nota 16), pp. 19-20 [aquí, «explicativa» y «explicación» aluden a la fundamentación que hace explícito lo que está necesariamente implícito en una práctica (N. del T.)].

48 Más detalladamente, vid. AlEXY, «Teoría del discurso y derechos humanos» (nota 22), pp. 76-91.

49 Ibid., pp. 104-111.

50 Ibid., p. 86.

51 R. BRAndom, Articulating Reasons, Cambridge Mass., Harvard UP, 2000, p. 26. 
ción se puede denominar «existencial». Y aquí puede hablarse de «fundamentación» porque no estamos ante ninguna clase de preferencias que uno se saque de la manga, sino ante la confirmación de algo que ya por la vía de la explicación se ha demostrado necesariamente como posibilidad ${ }^{52}$.

\subsubsection{Democracia}

La segunda exigencia es la democracia. Hay nociones muy diversas de la democracia. El principio del discurso exige la democracia deliberativa. La democracia deliberativa es más que un procedimiento para establecer un equilibrio de intereses por debajo del umbral de la dictadura o la guerra civil. En ella, al plano de los intereses y del poder se superpone un plano de los argumentos, en el que todos los implicados discuten sobre la solución política correcta. La democracia deliberativa, por consiguiente, presupone la posibilidad de racionalidad discursiva. Si la racionalidad discursiva fuera imposible, la democracia deliberativa sería una ilusión.

Que la posibilidad de la democracia deliberativa dependa de la posibilidad de discursos prácticos racionales es solamente un lado del asunto. El otro es que sólo a través de la institucionalización de la democracia deliberativa puede realizarse la idea del discurso tanto como esta es realizable. Quien quiere corrección, tiene que querer discursos; y quien quiere discursos, tiene que querer democracia ${ }^{53}$.

\subsubsection{Jurisdicción constitucional}

Si el proceso de formación de la voluntad política discurre como es debido, la mayoría parlamentaria respetará y concretará tanto los derechos fundamentales como las reglas de la democracia deliberativa. Ahora bien, ¿qué sucede si se aprueban leyes que vulneran los derechos fundamentales, o que son incompatibles con los principios de la democracia deliberativa? Se puede entonces o confiar en el poder de auto-sanación de la democracia o instituir una jurisdicción constitucional. Es preferible lo segundo ${ }^{54}$. Toda jurisdicción constitucional, desde luego, encierra el riesgo de un paternalismo incompatible con la idea de autodeterminación democrática ${ }^{55}$. Pero el riesgo puede contrarrestarse si la jurisdicción constitucional se concibe como la representación argumentativa de los ciudadanos y si, en cuanto tal, tiene éxito ${ }^{56}$. Esto deja claro que el constitucionalismo democrático sólo es posible como un constitucionalismo discursivo $^{57}$.

52 Cfr. AleXY, «Menschenrechte ohne Metaphysik?» (nota 16), p. 21.

53 R. AleXY, «Ley Fundamental y teoría del discurso», trad. D. Oliver-Lalana, en N. Cardinaux, L. Clérico y A. D'Auria (eds.), Las razones de la producción del Derecho, Buenos Aires, Departamento de Publicaciones de la Facultad de Derecho (UBA), 2006, p. 30.

${ }^{54}$ ALEXY, «La institucionalización de los derechos humanos en el Estado constitucional democrático» (nota 4), pp. 39-41; ALEXY, «La institucionalización de la razón» (nota 3), pp. 242-243.

55 J. Habermas, Facticidad y validez, trad. M. JimÉnez Redondo, Madrid, Trotta, 1998, p. 339.

56 R. AleXY, «Ponderación, control de constitucionalidad y representación», trad. R. GONZÁLEZ DE LA Vega, en R. Alexy, Teoría del discurso y derechos constitucionales, México D. F., Fontamara, 2005, pp. 99-103.

57 Ibid., p. 89. 


\subsection{Argumentación jurídica}

Ningún legislador puede crear un sistema de normas tan perfecto que todos los casos se puedan resolver solamente en virtud de una simple subsunción de la descripción del estado de cosas bajo el supuesto de hecho de una regla. Hay varias razones para ello. De singular importancia resultan la vaguedad del lenguaje del Derecho, la posibilidad de antinomias, la falta de normas en las que pueda fundarse la decisión, y la posibilidad de decidir incluso, en casos especiales, contra el tenor literal de una nor$\mathrm{ma}^{58}$. En ese sentido existe una necesaria apertura del Derecho ${ }^{59}$. Y esto vale también, por lo menos en igual medida, para un sistema de precedentes.

En el ámbito de apertura del Derecho positivo, por definición, no se puede decidir sobre la base del Derecho positivo, pues si fuera posible hacerlo ya no estaríamos en el ámbito de apertura. Por eso, positivistas como Kelsen y HarT tan sólo son consecuentes cuando dicen que en el ámbito de apertura el juez está facultado para decidir, a semejanza del legislador, a partir de criterios extrajurídicos ${ }^{60}$. La pretensión de corrección conduce, por el contrario, a una interpretación no positivista. En el centro de esta interpretación no positivista se encuentra la tesis del caso especial.

La tesis del caso especial afirma que el discurso jurídico es un caso particular de discurso práctico general ${ }^{61}$. Al igual que en la argumentación práctica general, en la argumentación jurídica se trata siempre, en definitiva, de lo que está ordenado, prohibido y permitido, es decir, de cuestiones prácticas. Tanto en el discurso práctico general como en el discurso jurídico se efectúa una pretensión de corrección. La particularidad consiste en que, a diferencia de lo que ocurre en el discurso práctico general, en el discurso jurídico la pretensión de corrección no se refiere a qué es correcto con independencia del Derecho positivamente válido en cada caso, sino a qué es correcto dentro del marco de un sistema jurídico determinado. Lo que sea correcto en un sistema jurídico depende, en esencia, de lo que haya sido establecido autoritativa o institucionalmente y encaje en el sistema. Si se quiere expresar esto con una fórmula abreviada, puede decirse que la argumentación jurídica está sujeta a la ley y al precedente, y tiene que atender al sistema de Derecho elaborado por la dogmática jurídica ${ }^{62}$. Si la ley, el precedente o la dogmática establecen claramente la decisión, y no existen reparos serios en el aspecto de la corrección material, el caso se decidirá sólo mediante lo autoritativo e institucional. Pero cuando la ley, el precedente y la dogmática no fijan la respuesta a una cuestión jurídica, lo cual define los casos difíciles, son precisas valoraciones adicionales que no se pueden extraer sólo del material autoritativo preestablecido. Si se ha de satisfacer la pretensión de corrección, estas premisas adicionales tienen que justificarse. Y esto, si lo autoritativo o institucional por sí solo no ofrece ninguna respuesta, únicamente es posible por medio de la argumentación práctica general.

58 Cfr. ALEXY, Teoría de la argumentación jurídica (nota 18), pp. 23-24.

${ }^{59}$ Cfr. H. L. A. HART, El concepto de Derecho, Buenos Aires, Abeledo-Perrot, 1980, pp. 159-160.

${ }^{60}$ Kelsen, Teoría pura del Derecho (nota 31), p. 353; HART, El concepto de Derecho (nota 59), pp. 157 158,168 y $252-253$.

${ }_{61}$ AleXY, Teoría de la argumentación jurídica (nota 18), pp. 206-213.

62 Estas sujeciones se expresan con las reglas y formas específicas del discurso jurídico; cfr. ALEXY, Teoría de la argumentación jurídica (nota 18), pp. 213 y ss., 285-287. 
HABERMAS ha objetado, en contra de la tesis del caso especial, que el discurso jurídico no puede concebirse como un caso especial del discurso moral: «los discursos jurídi$\cos \left(\right.$...) no constituyen casos especiales de argumentaciones morales» ${ }^{63}$. La razón sería que en el Derecho, junto a los argumentos morales, también han de jugar algún papel los argumentos éticos y pragmáticos ${ }^{64}$. HABERMAS denomina «morales» a los argumentos que tratan de la justicia ${ }^{65}$. Las cuestiones éticas, en este caso ético-políticas, tendrían por objeto, en cambio, «la autocomprensión colectiva» ${ }^{66}$, lo cual incluiría las discusiones acerca de las tradiciones y valores comunes ${ }^{67}$. En cuanto a los argumentos pragmáticos, por último, se trataría de lograr un equilibrio entre intereses rivales por medio de la «negociación de compromisos» ${ }^{68}$. Sin duda, a la luz de estas distinciones, HABERMAS tiene razón con su tesis de que el discurso jurídico no es un caso especial del discurso moral, puesto que el discurso jurídico no sólo está abierto a los argumentos morales, sino también a los éticos y a los pragmáticos. Pero eso no afecta a la tesis del caso especial. Esta no dice que el discurso jurídico sea un caso especial del discurso moral, sino que constituye un caso especial del discurso práctico general. El discurso práctico general es un discurso en el que las cuestiones prácticas se responden con razones no autoritativas, las cuales comprenden tanto las razones morales como las éticas y pragmáticas. El discurso práctico general es, pues, un discurso donde se combinan las razones morales, éticas y pragmáticas. Esta combinación forma un vínculo sistemáticamente necesario en el que se manifiesta la unidad substancial de la razón práctica ${ }^{69}$. La pretensión de corrección se refiere aquí a las tres dimensiones, si bien la prioridad corresponde a las razones morales ${ }^{70}$. La tesis del caso especial expresa una conexión necesaria entre el Derecho y la moral por cuanto afirma que en el discurso jurídico se encuentra necesariamente incluido el discurso práctico general y, en este, el discurso moral.

\subsection{La teoría de los principios}

El sistema del constitucionalismo democrático quedaría incompleto sin la teoría de los principios. La base de la teoría de los principios es la distinción que la teoría de las normas establece entre reglas y principios ${ }^{71}$. Los principios son mandatos de optimización. Exigen que algo se realice en la mayor medida posible dentro de las posibilidades jurídicas y fácticas. Su forma de aplicación es la ponderación. En cambio, las reglas son normas que ordenan, prohíben o permiten algo definitivamente. En este sentido son mandatos definitivos. Su forma de aplicación es la subsunción.

La teoría de los principios es el sistema construido a partir de las implicaciones de esa distinción. Estas implicaciones afectan a todos los ámbitos del Derecho. Como

63 Habermas, Facticidad y validez (nota 55), p. 306.

64 Ibid., pp. 302-303.

65 Ibid., pp. 221 y ss.

66 Ibid., p. 173.

67 Ibid.

68 Ibid.

69 R. AleXY, «La tesis del caso especial», trad. I. LIFANTE, en Isegoría, 21, 1999, p. 29.

70 ALEXY, «Thirteen Replies» (nota 7), p. 355.

71 Cfr. Alexy, Teoría de los derechos fundamentales, trad. C. Bernal Pulido, Madrid, CEPC, 2." ed., 2007, pp. 67-68. 
hemos visto, afectan incluso al concepto de Derecho: el equilibrio correcto entre los principios de seguridad jurídica y justicia exige allí que la extrema injusticia no pueda ser Derecho, si bien, por debajo del umbral de la injusticia extrema, la injusticia no elimina el carácter jurídico o la validez jurídica. La teoría de los principios desempeña su papel principal en el campo de los derechos fundamentales. La razón más importante para ello es la relación de mutua implicación entre el carácter de principio y el principio de proporcionalidad. El principio de proporcionalidad, con sus tres subprincipios de idoneidad, de necesidad y de proporcionalidad en sentido estricto, se sigue lógicamente de la definición de los principios, y ésta de aquél ${ }^{72}$. Esto significa que si los derechos fundamentales tienen carácter de principios, entonces se aplica (gilt) el principio de proporcionalidad; y que si se aplica el principio de proporcionalidad, entonces los derechos fundamentales tienen carácter de principios.

Los subprincipios de idoneidad y necesidad exigen una optimización relativa a las posibilidades fácticas. Ahí no se trata de efectuar una ponderación, sino de evitar aquellas injerencias en los derechos fundamentales que son evitables sin detrimento de otros principios, es decir, se trata de la optimalidad de Pareto ${ }^{73}$. En cambio, en el caso del principio de proporcionalidad (Verbältnismäßigkeit) en sentido estricto — que también cabe denominar, sin más, «principio de proporcionalidad» (Proportionalität)—, se trata de una optimización relativa a las posibilidades jurídicas. Las posibilidades jurídicas, además de por reglas, quedan determinadas esencialmente por principios opuestos. Este es el terreno de la ponderación, pues la ponderación no consiste en nada más que en la optimización de principios opuestos. De ahí que esta teoría de los principios sea, ante todo, una teoría de la ponderación.

En la Teoría de los derechos fundamentales he intentado capturar o reflejar la estructura de la ponderación con ayuda de dos leyes: la ley de colisión y la ley de ponderación. Aquí sólo ha de interesar la ley de ponderación ${ }^{74}$. Reza como sigue:

«Cuanto mayor es el grado de la no satisfacción o de afectación de uno de los principios, tanto mayor debe ser la importancia de la satisfacción del otro ${ }^{75}$ ».

La ley de ponderación expresa el núcleo de una estructura que es posible reflejar completa y exactamente con ayuda de una fórmula que he denominado «fórmula del peso» ${ }^{76}$ :

$$
G_{i, j}=\frac{I_{i} \cdot G_{i} \cdot S_{i}}{I_{j} \cdot G_{j} \cdot S_{j}}
$$

« $\left.G_{i, j}\right\rangle$ representa el peso concreto de un principio $P_{i}$ en relación con el principio en colisión $P_{j}$. Si $G_{i, j}$ es mayor que 1 , prevalece $P_{i}$; si $G_{i, j}$ es menor que 1 , prevalece $P_{j}$. Si $G_{i, j}$ adopta el valor 1, existe un empate o situación de igualdad, para cuya solución son precisas consideraciones adicionales. La fórmula del peso define $G_{i, j}$ como el cociente del producto de tres factores referidos a cada uno de los principios. En el lado de $P_{i}$

72 Ibid., pp. 91-95.

73 Ibid., p. 141.

${ }^{74}$ Acerca de la ley de colisión, $c f r$. AleXY, ibid., pp. 75-76.

75 Ibid., p. 138.

76 R. AlEXY, «La fórmula del peso», trad. C. Bernal Pulido, en R. Alexy, Teoría de la argumentación jurídica (nota 18), p. 371. 
son la intensidad de la injerencia en $P_{i}\left(I_{i}\right)$, el peso abstracto de $P_{i}\left(G_{i}\right)$ y la seguridad de las apreciaciones o asunciones empíricas acerca de lo que la ejecución de la medida evaluada significa para la no realización de $P_{i}\left(S_{i}\right)$. Los factores correlativos, en el lado de $P_{j}$ son la intensidad de la injerencia en $P_{j}$ que resultaría de la no injerencia en $P_{i}\left(I_{j}\right)$, el peso abstracto de $P_{j}\left(G_{j}\right)$ y la seguridad de las apreciaciones empíricas acerca de lo que la omisión de la medida evaluada significaría para la realización de $P_{j}\left(S_{j}\right)$.

Estos seis factores pueden valorarse con ayuda de escalas como «leve» $(l)$, «medio» $(m)$ y «grave» $(s)$; desde luego, sería posible afinar esta escala, aunque debido a la naturaleza del Derecho constitucional en seguida toparíamos con límites ${ }^{77}$. Para calcular el valor de $G_{i, j}$ hemos de asignar cifras a $l, m$ y $s$. Para ello se puede emplear la secuencia geométrica $2^{0}, 2^{1}, 2^{2}$, esto es, $1,2,4^{78}$.

Uno podría pensar que así se reemplaza la argumentación por el cálculo, y que eso no es posible en el Derecho. Pero a esto hay que responder que los números o cifras no sustituyen a los juicios o a las proposiciones, sino que únicamente los representan. $P_{i}$ representa el Derecho fundamental a la libertad de expresión. Si se asigna el valor 1 a $I_{i}$, entonces 1 representa el juicio «la injerencia en la libertad de expresión es leve». Este juicio, como todos los juicios, precisa de una fundamentación por medio de argumentos. Ocurre aquí lo mismo que con las premisas de la fórmula de la subsunción ${ }^{79}$. Esto deja claro que la fórmula del peso no es sino una forma de argumento ${ }^{80}$ del discurso práctico. En cuanto forma de argumento, la fórmula del peso no es un rival del discurso práctico racional, sino uno de sus elementos ${ }^{81}$.

Así pues, la teoría de los principios conecta la teoría de los derechos fundamentales y la teoría de la argumentación en una unidad necesaria. Si a eso añadimos que resulta posible construir sobre esta base una teoría de los márgenes de acción del legislador que permita una delimitación razonable de las competencias del tribunal constitucional respecto de las del Parlamento ${ }^{82}$, entonces quedan reunidos los elementos principales del sistema del constitucionalismo democrático. Si lo ideal puede conciliarse con lo real, es en este intento de institucionalizar la razón.

\section{(Traducción de A. Daniel Oliver-Lalana)}

\footnotetext{
77 R. Alexy, «On Balancing and Subsumption», Ratio Juris, 16, 2003, p. 445.

78 ALEXY, «La fórmula del peso» (nota 76), p. 365.

79 ALEXY, «On Balancing and Subsumption» (nota 77), p. 448.

80 Cfr. Alexy, Teoría de la argumentación jurídica (nota 18), pp. 102-103.

81 Indicios de la fórmula se encuentran ya en el canon de reglas de la Teoría de la argumentación jurídica (nota 18), cfr. p. $196(4.5,4.6)$.

82 R. ALEXY, «Derecho constitucional y Derecho ordinario. Jurisdicción constitucional y jurisdicción ordinaria», trad. C. BERnAl Pulido, en R. AlEXY, Tres escritos sobre los derechos fundamentales y la teoría de los principios, Bogotá, Universidad Externado de Colombia, 2003, pp. 57-87.
} 